\title{
A Suspected Detached Pars Plana Cyst in the Vitreous Cavity
}

\author{
Mukesh Kumar, MS'; Abhishek Varshney, MS $^{\mathbf{2}}$ \\ ${ }^{1}$ Department of Glaucoma Service, C L Gupta Eye Institute, Ram Ganga Vihar, Moradabad, India \\ ${ }^{2}$ Department of Vitreoretina, C L Gupta Eye Institute, Ram Ganga Vihar, Moradabad, India \\ ORCID: \\ Mukesh Kumar: https://orcid.org/0000-0002-9126-5113
}

J Ophthalmic Vis Res 2020; 15 (4): 579-580

\section{PRESENTATION}

A 35-year-old woman presented with the chief complaint of bilateral ocular itching. There was no history of ocular trauma or previous eye surgery. Vision in both eyes was 20/20 with N6 near vision, normal anterior segment, and an intraocular pressure of $8 \mathrm{mmHg}$ in both eyes. Fundus examination revealed a clear media. A 2-3 mm, oval-shaped, brown-pigmented cyst that was not mobile with ocular movement was present in the vitreous cavity of the right eye. The patient was asymptomatic at the time of examination. No treatment was performed; ultrasound biomicroscopy was advised, but the patient did not come for further evaluation.

\section{DISCUSSION}

Vitreous cysts can be classified as congenital or acquired. Congenital cysts are stable, ovalshaped, and not associated with any other ocular pathology. These cysts are remnants of the hyaloid vascular system. ${ }^{[1]}$ Non-pigmented cysts are usually located in the posterior vitreous; pigmented cysts arise from the iris or ciliary body

Correspondence to:

Mukesh Kumar, MS. C L Gupta Eye Institute, Ram Ganga Vihar, Phase 2(Ext) Moradabad 244001, India.

E-mail: mukkimedico@yahoo.com

Received: 29-10-2018Ａccepted: 16-07-2020

\section{Access this article online}

Website: https://knepublishing.com/index.php/JOVR

DOI: $10.18502 /$ jovr.v15i4.7799 pigment epithelium and may migrate into the anterior chamber or the vitreous cavity. ${ }^{[2]}$ Acquired vitreous cysts may result from ocular trauma, toxoplasmosis, ${ }^{[3]}$ or intermediate uveitis. ${ }^{[4]}$ They may be associated with high myopia and choroidal coloboma. ${ }^{[5]}$ Intraocular medulloepithelioma may also present as a free-floating vitreous cyst. ${ }^{[6]}$

Dislocated pars plana cyst in the vitreous is an uncommon finding. As this patient was asymptomatic and had no history of ocular trauma, we assumed that the cyst had been dislocated from its primary position.

\section{Acknowledgement}

Authors would like to acknowledge the technical support provided by Mr. Lokesh Chauhan.

\section{Financial Support and Sponsorship}

Nil.

\section{Conflicts of Interest}

There are no conflicts of interest.

This is an open access journal, and articles are distributed under the terms of the Creative Commons Attribution-NonCommercial-ShareAlike 4.0 License, which allows others to remix, tweak, and build upon the work non-commercially, as long as appropriate credit is given and the new creations are licensed under the identical terms.

How to cite this article: Kumar M, Varshney A. A Suspected Detached Pars Plana Cyst in the Vitreous Cavity. J Ophthalmic Vis Res 2020;15:579-580. 

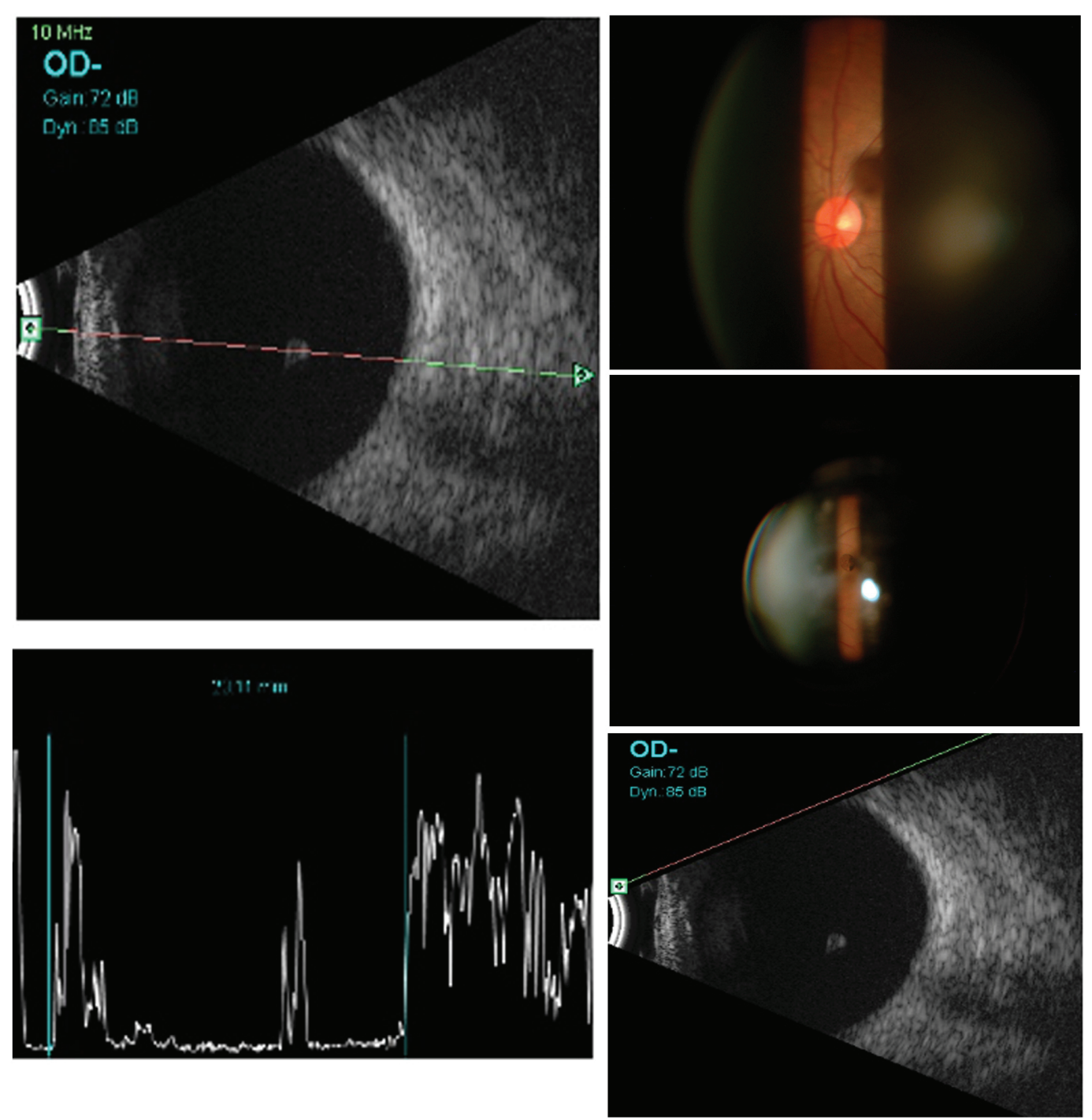

Figure 1. B-mode ultrasound with a $10 \mathrm{MHz}$ probe showing a free-floating globule in the vitreous with a hyperechoic surface, and hypoechoic interna, suggestive of a vitreous cyst. Corresponding A-mode ultrasound shows to be normal. Slit lamp biomicroscopy photographs showing a cyst in the vitreous and a normal posterior pole of the right eye.

\section{REFERENCES}

1. Bullock JD. Developmental vitreous cysts. Arch Ophthal 1974;91:83-84.

2. Lisch W, Rochels R. Pathogenesis of congenital vitreous cysts. Klin Monbl Augenheilkd 1989;195:375-378. [in German].

3. Pannarale $\mathrm{C}$. On a case of preretinal mobile cysts in a subject affected by congenital toxoplasmosis. G Ital
Oftalmol 1964;17:306-317. [in Italian]

4. Tranos PG, Ferrante P, Pavesio C. Posterior vitreous cyst and intermediate uveitis. Eye 2010;24:1115-1116.

5. Tuncer S, Bayramoglu S. Pigmented free-floating vitreous cyst in a patient with high myopia and uveal coloboma simulating choroidal melanoma. Ophthalmic Surg Lasers Imaging 2011,42:49.

6. Saunders T, Margo CE. Intraocular medulloepithelioma. Arch Pathol Lab Med 2012;136:212-216. 